\title{
Notas sobre los aportes de Aralia López González a la crítica literaria: una breve revisión
}

\section{Notes on Aralia López González's Contribution to Literary Criticism: A Brief Review}

\author{
Gerardo Bustamante Bermúdez \\ Universidad Autónoma de la Ciudad de México \\ gerardbb81@hotmail.com
}

\author{
Yyo aquí \\ me contemplo en la escritura. \\ Un país sin invierno, Aralia López
}

Resumen: En este texto se hace una breve revisión del aporte de Aralia López González como historiadora de la literatura latinoamericana - con particular énfasis en la narrativa mexicana-y su particular realización en escritoras nacidas a principios del siglo pasado y en textos publicados hasta la década de los noventa. Atenta al tema de la escritura de mujeres, la investigadora dedicó gran parte de su vida académica a observar, desde los estudios literarios y culturales, la recepción crítica y editorial de la escritura de mujeres, así como los temas y la estética en que se desenvuelven tanto escritoras consagradas como marginadas. La posibilidad de estudiar este corpus textual fue una forma de hacer visibles las voces femeninas, incluyendo la de la propia investigadora y la de las demás escritoras y críticas literarias.

Palabras clave: escritoras, Aralia López, crítica literaria

Abstract: This paper is a brief review of the contribution of Aralia López González as historian of Latin American literature, with particular emphasis on the Mexican narrative and its particular development in women writers born at the beginning of the last century and texts published until the nineties. Attentive to the issue of feminine writing, the researcher dedicated a large part of her academic life to observe, from the perspective of literary and cultural studies, the critical and 
editorial reception of women's writing, as well as the themes and aesthetics in which consecrated and even marginalized women writers flourish. The possibility of studying this textual corpus was a way of making female voices visible, including that of the researcher herself and that of other writers and literary critics.

Keywords: $\quad$ female writers, Aralia López, literary criticism

Recibido: $\quad 16$ de agosto de 2019

Aceptado: $\quad$ o2 de octubre de 2019

1. La escritura como ejercicio intelectual, ya sea en la narrativa y la poesía, así como en la crítica literaria y la teoría, son, dentro de la obra de Aralia López González, contribuciones útiles y prácticas de resistencia cultural y también interpretaciones alternativas sólidas en el mundo académico en el que desarrolló su quehacer como pensadora latinoamericana y formadora de generaciones de estudiantes universitarios de licenciatura y posgrado. Los intereses temáticos de la investigadora son parte de sus pasiones y luchas por representar, pensar y repensar los diferentes espacios socioculturales e históricos desde donde escriben las mujeres, ya sea como escritoras de textos literarios o como críticas y teóricas de la literatura en México. ${ }^{1}$ En este universo de ideas se desarrolla el legado escrito de Aralia López, que va del pensamiento lati-

1 Dentro de los estudios literarios sobre género en México es pertinente referir los trabajos del Taller de Teoría y Crítica Literaria Diana Morán, que nació en la Ciudad de México en 1984 como continuación del Programa Interdisciplinario de Estudios de la Mujer, de El Colegio de México. A partir de 1993 las investigadoras se agruparon con el nombre de la escritora y crítica panameña Diana Morán. Algunas de las integrantes que han aportado estudios acuciosos sobre la producción de mujeres, son, además de la propia Aralia López: Ana Rosa Domenella, Nora Pasternac, Luzelena Gutiérrez de Velasco, Ute Seyde, Adriana González Mateos, Aline Pettersson, Berenice Romano Hurtado, Luz Elena Rodríguez Zamudio, Maricruz Castro Ricalde, Laura Cázares, entre otras más. Fruto de los años de estudio como grupo podemos enunciar los títulos: Escribir la infancia. Narradoras mexicanas contemporáneas (1996), compilación de Nora Pasternac, Ana Rosa Domenella y Luzelena Gutiérrez de Velasco; Territorio de leonas. Cartografía de narradoras mexicanas en los noventa (2001), coordinado por Ana Rosa Domenella; Las voces olvidadas. Antología crítica de narradoras mexicanas nacidas en el siglo XIX (1997), edición de Ana Rosa Domenella y Nora Pasternac; Territorio de escrituras. Narrativa mexicana del fin de siglo (2005), coordinado por Nora Pasternac, entre otros libros colectivos. Además de estos títulos, en años recientes el grupo de investigadoras emprendió el proyecto editorial Desbordar el Canon, en donde, a manera de estudios literarios, se han ocupado de la obra de autoras como Elena Garro, Rosario Castellanos, Nellie Campobello, Amparo Dávila, María Luisa Puga, Luisa Josefina Hernández, Esther Seligson, Julieta Campos, Josefina Vicens, entre otras, 
noamericano y los estudios sobre el indigenismo, pasando por asuntos sobre la nación, la identidad en obras literarias, así como sus importantes estudios críticos sobre la obra de Rosario Castellanos —además de varios artículos dedicados a esta autora, su libro La espiral parece un círculo (López 1991a) ha sido por décadas un texto clásico- - Como crítica y antologadora de escritoras mexicanas y latinoamericanas es que resulta pertinente quizá, emprender un trabajo más extenso de reediciones del legado de Aralia López como crítica literaria, filóloga, pensadora y difusora de la literatura. ${ }^{2}$

Los aportes de Aralia López González son académicos y literarios. Como pensadora, su paso por el Programa Interdisciplinario de Estudios de la $\mathrm{Mu}-$ jer, de El Colegio de México; el Taller de Teoría y Crítica Literaria Diana Morán, desde la Universidad Autónoma Metropolitana, Unidad Iztapalapa, la visibilizan como una intelectual que establece discusiones entre pares que abordan temas similares, hacen propuestas, construyen marcos teóricos y metodologías de estudio, principalmente a partir de la revisión del estado del arte en los estudios literarios para, a partir de ahí, contribuir con textos que resultan necesarios y pertinentes. La inclusión de temas y propuestas es sin duda un reto académico en el que Aralia López fue pionera en México, porque, más allá de su conocimiento teórico sobre de la literatura, su singular abordaje de los textos (a partir de la sociocrítica, la teoría literaria en general, el feminismo y el psicoanálisis), hace posible que sus estudios sirvan para pensar de manera lúcida y propositiva otras realidades latinoamericanas, particularmente en temas de género.

Es sustantivo resaltar que, en el caso de la crítica literaria en México, hasta los años setenta aproximadamente y, de forma particular en las instituciones de educación superior, los planes y programas de cursos no incluían de forma específica el abordaje desde el feminismo y los estudios de género; de

dialogando con la crítica existente y haciendo sus propios aportes, particularmente de obras y tópicos poco explorados.

2 El aporte bibliográfico de Aralia López es extenso; para ello hay que referir algunos de sus textos previos a los textos comentados en este artículo, pues al inicio de su carrera como crítica literaria feminista también se observan otras aportaciones, a saber: Acotaciones sobre varios autores mexicanos (1972), Sexo, violencia y drogas. Ensayos psicoanalíticos y literarios (1975), Así escriben los niños en México (1982), además de un centenar de ensayos y artículos que aparecieron en revistas y periódicos, como Cuadernos Americanos, Signos Literarios, Literatura Mexicana, Los Universitarios, Cambio, "El Gallo Ilustrado", de El Día, entre otros. Para un informe detallado de la bibliografía de la autora, consúltese <http://dcsh.izt.uam.mx/licenciaturas/letras_hispanicas/wp-content/ uploads/2018/o4/Aralia-L\%C3\%B3pez-1.pdf>. 
ahí la importancia de reconocer que la integración de cuerpos colegiados de mujeres en diferentes disciplinas supone no solo una producción intelectual, sino de recursos humanos agrupados en proyectos, grupos y centros de investigación. ${ }^{3}$

Los aportes de Aralia López a los estudios literarios, con especial atención a los textos escritos por mujeres, son varios. De sor Juana Inés de la Cruz a Rosario Castellanos, pasando por María Luisa Puga, Esther Seligson, Elena Garro, María Luisa Mendoza, Rosario Ferré y otras más, constituyen en varios sentidos la plataforma de los estudios literarios de corte feminista y un diálogo académico en la formación de generaciones de estudiantes y críticos literarios en México.

En este artículo se hace una revisión de algunos de los aportes de Aralia López para dilucidar el ejercicio de la crítica literaria, con énfasis en la escritura de mujeres y su visibilización dentro del panorama literario mexicano, toda vez que antes de la aparición de su libro De la intimidad a la acción. La narrativa de escritoras latinoamericanas y su desarrollo (1985), existían muy pocos textos valorativos sobre el quehacer literario de mujeres en América Latina, al menos desde el abordaje teórico y metodológico con el que la autora analiza un corpus poco visible para los críticos hombres de hace algunas décadas. Abarcar todo su corpus crítico resulta imposible, por eso, a manera de notas, solo me referiré a sus primeros aportes.

2. En "Anticipaciones feministas en la vida y en la obra de sor Juana Inés de la Cruz" (1993), Aralia López elabora un acercamiento al pensamiento y autorrepresentación que hace la monja jerónima en algunos de sus poemas y en su "Respuesta a sor Filotea de la Cruz". Para entender y explicar a sor Juana desde los preceptos feministas, la investigadora dialoga con los postulados de Carolyn G. Heilbrun y Alexandra Kollontay, así como con la construcción de sor Juana que hace Octavio Paz en su libro Las trampas de la

3 Centro Universitario de Investigaciones y Estudios de Género (antes PUEG) de la unAm; Centro de Estudios de Género, de la Universidad de Guadalajara; Centro de Estudios de Género, de la Universidad Veracruzana; Centro de Estudios de Género, de la Benemérita Universidad Autónoma de Puebla; Programa Interdisciplinario de Estudios de Género, de El Colegio de México; la Especialización y Maestría en Estudios de la Mujer, de la Universidad Autónoma Metropolitana, Unidad Xochimilco, entre otros centros universitarios, han permitido, a partir de seminarios, congresos, posgrados y publicaciones, la difusión y promoción de las ideas sobre el feminismo y el género. 
$f e$. Para hablar sobre anticipaciones feministas en la vida y obra de sor Juana, la investigadora parafrasea a Heilbrun, quien señala que los hombres solo pueden ser y sentirse hombres frente a mujeres no ambiguas; y define como "mujeres no ambiguas a las que ponen en el centro de su vida a un hombre" (López 1993: 341). Sor Juana, por tanto, es una mujer ambigua y, además, célibe, en el sentido de que hay un predominio del quehacer intelectual por encima del proyecto de la función esposa-madre; la investigadora diserta sobre el contexto colonial al hablar sobre la inteligencia y el ejercicio de una feminidad exclusivamente pensante en sor Juana, en un contexto de opresión en el que se representa como un cuerpo subjetivo, en el que la religión no logró acabar con su imaginación. Dice la investigadora: "Si entendemos la categoría de género, o lo femenino, como una construcción histórica y cultural y no como una naturaleza o esencia innatas cuya fuente es el sexo biológico, entenderemos entonces el feminismo y también la institución o la rebeldía de ciertas mujeres como una crítica a la cultura y una práctica política contra la opresión" (López 1993: 342). En su estudio, la investigadora advierte el androcentrismo cultural, la masculinización colonial en los espacios de visibilización patriarcal y eclesiástico, pero dimensiona a la autora del virreinato desde su derecho disidente a pensar y existir desde una singular subjetividad a través de la escritura. Quien es visible por sus aportes, tiene derecho a existir y, desde ese punto de vista, la concepción que Aralia López tiene sobre la connotada escritora de la Colonia es la de una mujer visionaria que ha sido precursora del feminismo en México. Sirva este primer acercamiento de Aralia a sor Juana para justificar el derecho de las mujeres a pensar desde la resistencia su contexto social, familiar, religioso y cultural. Sor Juana Inés de la Cruz ha sido para muchas escritoras una especie de estandarte para sobrevivir en un espacio predominantemente masculino.

Pero, en el ámbito de los estudios literarios de López González, uno de sus primeros aportes es el libro De la intimidad a la acción. La narrativa de escritoras latinoamericanas y su desarrollo, dividido en nueve capítulos breves y un apartado de conclusiones, en el que la investigadora realiza un recorrido por la producción de 13 escritoras latinoamericanas que muestran diversas preocupaciones temáticas, según su contexto cultural. El periodo que elige López va de 1924 a 1975. Se trata de un libro un tanto monográfico; la autora parte de la premisa de que históricamente la presencia de las mujeres en el ámbito literario se ha dado a partir de la discriminación, la explotación y la opresión, por lo que "la literatura escrita por mujeres en Latinoamérica 
y la escrita por hombres tenían que ser, necesariamente, diferentes en sus motivos, contenido y evolución" (López 1985: 10). La irrupción de escritoras latinoamericanas en el contexto del auge de escritores como Jorge Luis Borges y Macedonio Fernández en Argentina; el grupo Contemporáneos en México; el Grupo Guayaquil, en Ecuador; así como otros grupos, revistas y autores, se da a partir de una nula recepción de la obra escrita por mujeres por parte de la crítica literaria, o bien, por el uso de calificativos como "novelita" o "princesa de la escritura" que algunos críticos de la década de los años veinte del pasado siglo utilizaron para referirse a escritoras con cierta "gracia", como la chilena María Luisa Bombal, mujer atípica, cuya aparición desestabiliza el concepto de canon literario de su época.

Al hablar sobre la producción y propuestas literarias de escritoras latinoamericanas, Aralia López propone estudiarlas bajo las nomenclaturas de "ser", "estar" y "accionar". En el primer caso se refiere al derecho femenino de existir como escritora; en el segundo, al hecho de permanecer, y el tercero, a incidir en una visión de mundo; pues de acuerdo con la autora

el proceso dentro del cual se desarrolla la narrativa escrita por mujeres en América Latina es inverso al de la literatura escrita por hombres. Mientras en estos el proceso va de lo exterior a una integración de las dos líneas, en ellas va de lo interior hacia la integración del ser con el estar y el accionar. Ambos procesos llegan al mismo punto en su desarrollo y maduración, pero por caminos inversos (López 1985: 26).

Ese análisis de la diferencia entre el estar y el accionar de los escritores y las escritoras latinoamericanos me hace pensar en las coincidencias con otras propuestas teóricas y el pensamiento de Aralia, quien en esos años estaba plenamente enterada de conceptos como écriture féminine, de Hélène Cixous (2001); 4 la teoría de "la página en blanco", de Susan

4 Cixous fue pionera en los estudios académicos teóricos y literarios sobre la escritura de mujeres; intentó deconstruir los discursos falocentristas y de subordinación de lo femenino a todo lo que tiene que ver con las leyes masculinas de la cultura occidental. Dialogó con el psicoanálisis y el simbolismo. La importancia de que las mujeres escriban es, para esta autora, una posibilidad de transformación del destino real y literario con el que se les representa desde la visión masculina, por ejemplo, en los cuentos de hadas. Para lograr este fin, es necesario que las autoras hablen desde el cuerpo, es decir, desde el conocimiento de lo que culturalmente les ha sido negado como discurso. El concepto 'procreación' debe salir del ámbito biológico y expandirse al pensamiento y al discurso. La autora relaciona la libido femenina con la creación y la tinta blanca, con la leche materna. En síntesis, el concepto 'escritura 
Gubar;5 el desarrollo de la ginocrítica ${ }^{6}$ de los años setenta del siglo xx y en otros asuntos sobre anatomías textuales, representaciones sobre el sexo/ género y los estudios sobre deconstrucción, no obstante, para este trabajo la autora está interesada en hacer una revisión sobre la recepción crítica de la obra de mujeres y, a partir de esto, establecer marcos teóricos latinoamericanos propios. En este sentido, lo que plantea Aralia López es una revisión de los textos escritos por mujeres para comprender aspectos como la sexualidad, las preocupaciones y representaciones de la escritura femenina, así como la inscripción de los textos que revisa dentro de un canon cultural muchas veces soterrado por la falta de difusión y valoraciones.

La investigadora observa tres momentos dentro de la tradición literaria en Latinoamérica en los que las mujeres escritoras que estudia se han desarrollado. El primero corresponde a la idea de represión y opresión sexual, en la venezolana Teresa de la Parra, con Ifigenia; en la chilena María Luisa Bombal, con La amortajada, y en la uruguaya Clara Silva, con El alma y los perros. El segundo es la opresión por la reproducción y la crianza de los hijos y la incipiente actitud crítica de las mujeres al ver a los hijos como un obstáculo de realización personal. Lo ejemplifica a través del análisis de las obras: Mañana digo basta, de la argentina Silvina Bullrich; La ruta de la evasión, de la costarricense Yolanda Oreamuno y Un aprendizaje o el libro de los placeres, de la brasileña Clarice

femenina' alude a la inscripción del cuerpo femenino y a la diferencia de lo femenino, es decir, a las diferentes maneras de ser mujer en el lenguaje y por lo tanto en el texto.

5 A grandes rasgos "la página en blanco" se refiere a la necesidad de las mujeres de escribirse desde la experiencia y la imaginación, más que a ser escritas por los escritores. La mujer como autora y texto tiene la posibilidad de inscribir un discurso en una página, pues dice Gubar: "las páginas manchadas son residuos biográficos de existencias de otra manera mudas, resultado de la vida y respuesta a ella más que un esfuerzo por producir un objeto estético independiente" (2001: 182-183). Esa manera de hacerse texto resulta una necesidad para las escritoras en el sentido en que son productoras de arte y, por ende, la sexualidad se identifica con la textualidad y la visión que de sí y del mundo tengan las escritoras.

6 El término fue acuñado y desarrollado por Elaine Showalter (2001) al referir el inicio de un proceso de redefinición de lo femenino desde la dimensión biológica, corporal, psíquica y cultural. Es necesario reinventar el lenguaje y hablar al margen de las estructuras falocéntricas, según lo indica la autora en "La crítica literaria en el desierto". El debate sobre el lenguaje y la cultura es uno de los aspectos más importantes de la ginocrítica, sobre todo porque se pone énfasis en la diferencia de las propias mujeres escritoras en asuntos de clase social, raza, nacionalidad e historia. Tiene destacada importancia para esta teoría hablar desde el cuerpo individual y la experiencia y no desde la definición genérica de los cuerpos de las mujeres como un discurso único, sino, por el contrario, diversos entre sí. 
Lispector. El tercer momento corresponde a la época en que las escritoras se asumen desde una actitud de liberación en el rol de esposa y madre, lo que estudia Aralia en las novelas: La pareja de Núñez, de Gloria Alcorta; El incendio y la víspera, de Beatriz Guido; Los que viven por sus manos, de Martha Mercader, las tres escritoras argentinas; la mexicana Rosario Castellanos, con Oficio de tinieblas; la cubana Nivaria Tejera, con Sonámbulo del sol; la colombiana Albalucía Angel, con Dos veces Alicia, y la también colombiana Fanny Buitrago, con El hostigante verano de los dioses. En este tercer grupo, López González destaca la contribución de las mujeres a un discurso más participativo en cuanto a temas como la violencia, el auge de las guerrillas latinoamericanas, la convicción revolucionaria e ideológica y el interés por los conflictos bélicos nacionales e internacionales. Así, en las escritoras de este tercer grupo: "Podemos concluir que a mayor contacto con el mundo en un sentido nacional y universal, mayor espesor e interiorización y, asimismo, mayor accionar dentro del mundo" (López 1985: 140). Este cambio en temáticas dentro de la narrativa latinoamericana de mujeres es el resultado de luchas e intereses de las propias escritoras para encontrar una forma de ser parte de la acción social; son las escritoras las que en la medida en que amplían su horizonte ideológico y de experiencias psicosociales, pueden escribir sobre otros temas más allá del matrimonio y la maternidad como asignaciones. La voz femenina, por tanto, se diversifica en el legítimo derecho que las condiciones políticas y culturales de sus respectivos países les van dando como respuesta a la lucha histórica por ser, estar y accionar en el mundo. Las mujeres de los años setenta viven de una manera distinta a las de sus madres y abuelas. A finales de la década de los cuarenta, Rosario Castellanos escribía en Sobre cultura femenina (1950):

Pero he aquí que vienen las mujeres a la literatura trayendo a cuestas sus sentimientos maternales frustrados, esos sentimientos en cuya satisfacción encuentran la inmortalidad [...] y en cuyos frutos, los hijos, se les presenta, como dice Freud, una parte de su propio cuerpo como un objeto exterior pero todavía íntimo, acaso, no tanto de que sus biógrafos no conocieran bien sus cualidades y las disminuyeran con notoria injusticia, sino más bien de que no existieran sus biógrafos. Para no correr ese riesgo acometieron por sí mismas la empresa y lo hicieron con amor, con un amor en el que no se les enfrentaría nunca rival tan rendido (Castellanos 2005: 209-210).

Esta experiencia de la mujer dentro del espacio literario y los temas sobre los que habla, los estudia Aralia López en De la intimidad a la acción (1985). 
Sobre el primer grupo de mujeres, la investigadora destaca, en el caso de Teresa de la Parra, la condición de la protagonista de Ifigenia: diario de una señorita que escribió porque se fastidiaba (1924), que llega al matrimonio como una ineludible condición social de género, pues el personaje "cumple su destino casándose, sin entrar en el matrimonio en sí: el libro se resuelve en los antecedentes, en la preparación de una joven para que cumpla ese 'destino' único y, por eso 'terrible'" (López 1985: 83). La obra de la escritora venezolana es una novela de formación en la que la protagonista concluye que su destino es el matrimonio porque existe una asignación cultural para ello. Por su parte, La amortajada (1938), de María Luisa Bombal, nos presenta a Ana María, la protagonista, quien experimenta una insatisfacción matrimonial, por eso se revela

como un ser agobiado, atropellado, nulo, un cuerpo tratado como propiedad narcisística de Antonio. [Frente a la insatisfacción, Ana María] recibirá el desprecio y la indiferencia, nunca la ternura; será desplazada inmediatamente en la vida del hombre que solo vio en ella un objeto de placer no un ser humano, y así lo comprenderá Ana María, arrastrando el matrimonio como único destino sin redención (López 1985: 92-93).

En tanto, la novela El alma y los perros (1962), de Clara Silva, es estudiada bajo la idea de que la educación femenina incluye, ineludiblemente, el compromiso social del matrimonio, así como una sexualidad al servicio del varón, más que al erotismo y a la sexualidad compartida, pues la protagonista incluso considera pecaminosa la idea del placer sexual. Estas tres obras dan cuenta de un destino social ineludible para las mujeres domesticadas en una tradición masculina, que se perpetúa, y en la cual no se tiene la posibilidad de pensar en otras realidades y realizaciones a partir de su propia elección, y de la enunciación de su cuerpo y deseo de forma libre.

3. En el libro de ensayos póstumos Declaración de fe (1997), Rosario Castellanos hace una revisión de las condiciones históricas de las mujeres en México, desde la época prehispánica hasta mediados del siglo xx. En la sección "La mujer en la época actual”, la escritora chiapaneca hace una revisión similar a la que elabora Aralia López en De la intimidad a la acción (1985). Le interesa a Castellanos analizar la "evolución" -incluso utiliza el mismo término que Aralia- de la condición social y de género de las mujeres dentro de la 
sociedad mexicana, ${ }^{7}$ sobre todo a partir de que "se comenzó a exigir la igualdad política del hombre y la mujer, el ejercicio del derecho de voto y la obligación del marido a legitimar todos los hijos habidos dentro y fuera del matrimonio" (Castellanos 1997: 101). Estas condiciones jurídicas de avanzada suponen también un cambio de paradigmas con respecto a las mujeres que pasan paulatinamente a ser agentes de acción, no obstante que en la revisión literaria de Rosario Castellanos sobre la producción de mujeres en los géneros de novelas, dramas y poesía, se señala que "no pueden ser tomados como productos estrictamente literarios. Falta, a más del cumplimiento de los requisitos formales, ese 'desinterés' tan peculiar del arte. Sobra el alegato, la necesidad de justificar una conducta ante una conciencia culpable, de analizar los motivos de un fracaso" (1997: 103). Al igual que Aralia López, Castellanos estudia la producción de obras literarias mexicanas y las divide en cuatro casos. El primero es el de Teresa Farías, cuya novela Como las aves, fue premiada en 1918, en un concurso convocado por el Departamento de Bellas Artes y la Universidad Nacional Autónoma de México. Castellanos opina que: "No vamos a analizarla desde el punto de vista de sus valores estéticos porque no resiste ni el más ligero análisis. Por su falta de malicia técnica, por su lenguaje rebuscado, por su exotismo y la improbabilidad de sus personajes, resulta completamente deleznable" (1997: 105). Pareciera que lo que más molesta a Castellanos es que la premiada escritora utilice la escritura literaria para seguir reproduciendo los códigos del patriarcado, la educación tradicional femenina con su correspondiente sumisión de género y lealtad al padre, al hermano y al marido; además, claro está, su desconocimiento de la técnica literaria. El mismo reproche le hace a la obra teatral La virgen fuerte, de María Luisa Ocampo, pues la protagonista experimenta y tiene la seguridad de que su condición de género la hace inferior a los hombres, por lo tanto, el recato y la fortaleza se dan en el espacio de la subordinación. La tercera escritora que comenta es Concepción Sada, autora de El tercer personaje y En silencio, dos obras dramáticas que muestran a dos mujeres médicas que aparentemente han logrado el éxito, pero descubren "que el éxito sí es posible pero no vale la pena. El éxito no ha contribuido a la felicidad personal de ellas. Al contrario, ha estorbado. Exige demasiados sacrificios y la compensación no deja nunca de ser abstracta, impalpable" (Castellanos 1997: 110). Frente a esta experiencia

7 Aunque Rosario Castellanos había escrito sobre esto desde 1948, Declaración de fe se publicó hasta 1997; de ahí la importancia de que Aralia coincida con ella sin haber conocido su texto. 
de reproducción de roles tradicionales, Castellanos observa una actitud masoquista en las mujeres, pues

se asombran y escandalizan de la pasividad sin protesta con que las mujeres mexicanas aceptan las humillantes condiciones de su vida familiar y social en las que, casi sin excepción, tienen que desenvolverse [...] encontramos que no hay una pasividad disgustada o indiferente sino un verdadero disfrute, una especie de embriaguez de la autoinmolación en el altar de un ídolo cuyos pies de barro son de todos conocidos: el hombre (1997: 111).

La cuarta escritora que Castellanos comenta como estereotipo de las incipientes madres literarias de principios del siglo Xx es Catalina D'Erzel, con su obra teatral Maternidad, en la que expone la vida cotidiana de una mujer y los problemas consabidos de ser esposa y madre, así como la abnegación como característica indispensable. La obra, al igual que las anteriores, carece de valor literario para ella, y solo reproduce una condición cultural: la abnegación como virtud femenina.

En este sentido, el estudio de Aralia López González continúa la apreciación que Rosario Castellanos hizo años antes de forma más virulenta y sarcástica. En De la intimidad a la acción (1985), Aralia se interesa en ubicar la producción de escritoras con un entorno sociocultural complejo y adverso, aunque, como Castellanos, se ocupa de dimensionar y entender la cultura patriarcal, la reproducción de roles y, sobre todo, el desarrollo de las mujeres; además, en el caso literario, lo hace afirmando que inicialmente la escritura en Latinoamérica es masculina, según la tradición. Las escritoras nacidas a finales del siglo XIX y principios del Xx son diferentes a las que nacieron ya en los años cuarenta. Quizá la evolución ideológica de estas últimas sea distinta, en el sentido de que su acceso a la educación formal, a la agrupación de su obra en publicaciones periódicas y al trabajo remunerado fuera del hogar, posibilita que esa alfabetización académica, creativa y económica produzca paulatinamente un cambio de paradigmas para que las mujeres se asuman como sujetos con derecho a estar y accionar en el mundo, más allá del reconocimiento y las luchas posteriores que han dado las mujeres, no solo en la igualdad legislativa en Latinoamérica, sino en su incursión como sujetos propositivos y como creadoras de discursos como mecanismo de defensa.

Las preocupaciones intelectuales de Aralia López sobre las mujeres escritoras fueron permanentes a lo largo de varias décadas. En su artículo "Narra- 
doras mexicanas: utopía creativa y acción" (1991b) hace una revisión sobre la capacidad de las escritoras en México para crear(se) e inventar(se) a través de la escritura. La investigadora habla sobre un segundo alumbramiento de las mujeres al crear una obra literaria y, además, diserta sobre la necesidad de construir marcos teóricos, revisiones monográficas individuales y colectivas donde las escritoras se asuman "como seres de lenguaje e intersubjetividad, vinculándose a la participación social” (López 1991b, 90). Son cinco años entre la publicación de La intimidad a la acción y este otro artículo, periodo en el que la nómina de escritoras mexicanas aumentó de manera considerable, pues Aralia revisa el caso de autoras como Nellie Campobello, Elena Garro, María Luisa Mendoza, Olga Harmony, María Luisa Puga, Luisa Josefina Hernández, Elena Poniatowska, Ángeles Mastretta y Laura Esquivel, pero también de otras más jóvenes como Brianda Domeq, Ethel Krauze o Gabriela Rábago Palafox. La noción de alumbramiento refiere un nacimiento textual desde la exploración íntima de las autoras y de los temas que les interesan; también con este concepto se afirma la necesidad de una educación y una cultura libresca como formación intelectual. En ese artículo, Aralia López agrupa a las escritoras según su desarrollo e intereses, pero también estudia la recepción editorial, la inclusión de la obra de escritoras en antologías, así como la importancia de hacer una crítica analítica, valorativa e interpretativa alrededor de las propuestas creativas de las mujeres que, además, viven de manera diferente a sus antecesoras, pues "en la actualidad, lo que predomina en las escritoras es la tendencia a profesionalizarse" (1991b: 101). La autora refiere el trabajo de algunas mujeres que se han desempeñado en el periodismo, la traducción y el trabajo editorial. Parte López de la hipótesis de que hay un antes y un ahora en la historia de las ideas y la cultura mexicana a partir de 1950, y que esa década supone cambios en la narrativa mexicana, ya que "Agotada la novela de la Revolución Mexicana y su tendencia social y realista, otras corrientes [...] aunque ya presentes con anterioridad (pervivencias del Modernismo y experimentación del Vanguardismo), asumen con vigor la escena literaria. Se robustece la tendencia hacia la interiorización de la conciencia y el tratamiento de la subjetividad" (1991b: 91). En su artículo también revisa y valora el trabajo genético Cuentistas mexicanas, siglo XX (1976), de Aurora M. Ocampo; 14 mujeres escriben cuentos (1975), de Elsa de Llarena; así como los dos tomos de La sombra fugitiva $(1985,1986)$, de Martha Robles, y Señas particulares: escritoras (1987), de Fabienne Bradu. Lo que hace Aralia en su importante artículo es hablar sobre la situación de la recepción crítica de la 
obra de escritoras mexicanas del siglo Xx, así como la profesionalización de la escritura y el 'desarrollo' estético de textos escritos por mujeres; el concepto 'desarrollo', en este caso significa la inclusión de las escritoras en escenarios más allá del doméstico, la cocina, la maternidad y el matrimonio como temas centrales. Revisar el texto De la intimidad a la acción (1985) y el artículo "Narradoras mexicanas: utopía y acción" (1991b) hace posible pensar en una evolución honesta y objetiva no solo en número de escritoras, sino en una diversidad de planteamientos y experiencias intersubjetivas que dan cuenta del accionar de los sujetos femeninos en el mundo personal y literario.

Aralia López González revisa la tradición; contextualiza la realidad histórica de las escritoras latinoamericanas; habla de los grupos y las publicaciones literarias en las que sobresalen los escritores, ya sea los del grupo Boedo y Florida, en Argentina, del grupo Contemporáneos en México y de otros más que impulsaron la visibilidad de escritores en el ámbito nacional e internacional a partir del siglo Xx. La ausencia de escritoras dentro de la nómina de esos grupos supone la inexistencia, el confinamiento a los temas inmediatos del yo, es decir, de la experiencia femenina desde la condicional del matrimonio y la maternidad, pero conforme la investigadora va revisando el mismo asunto en textos posteriores, se observa un avance, es decir, el camino para el desarrollo profesional de la escritura de mujeres comienza a ser relativamente más claro para la propia Aralia López, y otras investigadoras cercanas al tema, como las integrantes del Taller de Teoría y Crítica Literaria Diana Morán, que han estudiado la producción de autoras, su difusión, los premios literarios y los reconocimientos obtenidos. Al estudiar de forma individual y colectiva a las escritoras, también están hablando sobre ellas mismas y sus preocupaciones como personas inmersas en un mundo discursivo; tan es así, que el legado de Aralia López González, además de los hechos para la creación y la crítica literarias, fue el de ser la iniciadora de la Línea de Teoría Literaria en el Posgrado en Humanidades, de la Universidad Autónoma Metropolitana, y hacer visible el trabajo de creadoras literarias insertas en un campo literario minado por los hombres. Los textos de López González quebrantan los discursos hegemónicos, particularmente de las décadas de los setenta y ochenta del siglo pasado. Al hacer visible la producción literaria de mujeres, pugna por el reconocimiento al mérito artístico de quienes, como ella, utilizan la pluma para nombrarse.

Aralia López González es, a grandes rasgos, una pionera de la crítica y de la escritura de mujeres y de su evolución. Le interesan los avances, pero en sus 
investigaciones también marca los estancamientos de la literatura en general y sus posibles rutas para clasificar cierto tipo de escrituras que quedan al margen - como la de las mujeres y la de las llamadas minorías sexuales-; Aralia López fue de las primeras críticas literarias en escribir sobre Amora (1989), de Rosa María Roffiel, considerada la primera novela lésbica mexicana; también lo hizo al difundir entre sus estudiantes las novelas de autores como Luis Zapata. Siempre lúcida y propositiva, nos hereda una contribución útil a la escritura en general y a la escritura de mujeres en particular. Ya sea en Cuba, México o el resto de Latinoamérica, la voz siempre cálida y la inteligencia de nuestra querida maestra permanece en las conciencias de quienes revisamos sus aportes en estos tiempos aciagos en los que, de manera paradójica, al avance literario se impone la violencia, sobre todo en un país como México, con sus altos índices de feminicidios. Para muchos, el legado de Aralia López es inestimable porque su inteligencia y su escritura fueron y son una manera de luchar. A través del pensamiento luchó con fe por un mundo más libre. Ella nos enseña a leer a las autoras y autores, y desde ahí mirar nuestras diferencias.

\section{Bibliografía}

BRADU, Fabienne (1987). Señas particulares: escritoras. Ensayos sobre escritoras mexicanas del siglo XX. México, Fondo de Cultura Económica.

Castellanos, Rosario ([1948] 1997). Declaración de fe. Reflexiones sobre la situación de la mujer en México. México, Alfaguara.

Castellanos, Rosario (2005). Sobre cultura femenina. México, Fondo de Cultura Económica.

Cixous, Hélène ([1975] 2001). La risa de la medusa. Ensayos sobre la escritura. Traducción del francés de Ana María Moix. Barcelona, Anthropos.

GuBAR, Susan ([1997] 2001). “La página en blanco’ y los problemas de la creatividad femenina”, en Marina Fe (coordinación), Otra mente: lectura y escritura femenina. México, Universidad Nacional Autónoma de México, Fondo de Cultura Económica (Lengua y Estudios Literarios): 175-203.

López González, Aralia (1972). Acotaciones sobre varios autores mexicanos. México, Injuve.

López González, Aralia (1975). Sexo, violencia y drogas. Ensayos psicoanalíticos y literarios. México, Samo.

López González, Aralia, y Raúl Ávıla (1982). Así escriben los niños en México. México, Secretaría de Educación Pública/Comisión para la Defensa del Idioma Español. 
LóPEz González, Aralia (1985). De la intimidad a la acción. La narrativa de escritoras latinoamericanas y su desarrollo. México, Universidad Autónoma Metropolitana, Iztapalapa, Cuadernos Universitarias, núm. 23.

López González, Aralia (1991a). La espiral parece un círculo. La narrativa de Rosario Castellanos. Análisis de "Oficio de tinieblas" y "Álbum de familia”. México, Universidad Autónoma Metropolitana, Unidad Iztapalapa (Texto y Contexto, núm. 3).

López González, Aralia (1991b). “Narradoras mexicanas: utopía creativa y acción”, en Literatura Mexicana, vol. II, núm. 1, Instituto de Investigaciones Filológicas, Universidad Nacional Autónoma de México: 89-107.

López González, Aralia (1993). "Anticipaciones feministas en la vida y en la obra de sor Juana Inés de la Cruz", en Sara Poot Herrera (ed.). Y diversa de mí misma entre vuestras plumas ando. Homenaje internacional a sor Juana Inés de la Cruz. México, El Colegio de México, Programa Interdisciplinario de Estudios de la Mujer: 341-348.

LóPez González, Aralia (1998). Un país sin invierno. México, Paxis.

OcAмpo, Aurora M. (1976). Cuentistas mexicanas: siglo XX. México, Universidad Nacional Autónoma de México/Instituto de Investigaciones Filológicas (Nueva Biblioteca Mexicana, 45).

Paz, Octavio (2001). Las trampas de la fe. México, Fondo de Cultura Económica (Lengua y Estudios Literarios).

RoBles, Martha (1986). La sombra fugitiva. Escritoras en la cultura nacional, tomos I y II. México, Universidad Nacional Autónoma de México.

Rofiel, Rosa María (1989). Amora. México, Planeta.

Silva, Clara (1962). El alma y los perros. Buenos Aires, Fabril Editora.

ShOWALTER, Elaine ([1997] 2001). "La crítica feminista en el desierto", en Marina Fe (coordinación), Otra mente: lectura y escritura femenina. México, Universidad Nacional Autónoma de México, Fondo de Cultura Económica (Lengua y Estudios Literarios): 75-111.

\section{Gerardo Bustamante Bermúdez}

Doctor en Letras por la UNAM, maestro en Letras Mexicanas por la misma institución, y licenciado en Letras Hispánicas por la Universidad Autónoma Metropolitana. Ha publicado en revistas internacionales y libros colectivos más de treinta artículos críticos sobre escritores latinoamericanos. Sus líneas de investigación son los estudios sobre masculinidades diversas aplicados a la literatura latinoamericana y cubana de los siglos XX y XXI, así como la relación entre sociedad y literatura. Cuenta con un posdoctorado por parte de la Universidad Autónoma Metropolitana. Es profesor-investigador de la Universidad Autónoma de la Ciudad de México, en la Academia de Creación Literaria y miembro del Sistema Nacional de Investigadores (SNI), nivel I. 